\title{
Performance Analysis of Rectangular Concrete-Filled Steel Tubular Column under Earthquakes
}

\author{
Xinyu Mao ${ }^{1}$, Kun Zhao ${ }^{2}$ \\ ${ }^{1}$ Architectural \& Civil Engineering Design Institute Co., Ltd Hangzhou China, Hangzhou, 310000, China \\ ${ }^{2}$ Zhejiang Greentown Liuhe Architectural Design Co., Ltd., Hangzhou, 310000, China
}

Keywords: rectangular concrete-filled steel tubular column, frame structure, seismic performance

\begin{abstract}
The rectangular concrete-filled steel tubular column is a vertical bearing member, and it is easily damaged under the influence of the earthquake. Many reinforced concrete structures in China are in earthquake zones. When the load-bearing column is damaged and is not easy to repair, even if the structure does not collapse, it should be demolished and rebuilt. This paper discusses the destruction models of the earthquake to rectangular concrete-filled steel tubular column, analyzes the performance of rectangular concrete-filled steel tubular column under earthquake, and explores construction quality control and key technologies of the rectangular concrete-filled steel tubular column to provide some references for the relevant researchers.
\end{abstract}

\section{Introduction}

In recent years, the high-rise buildings in China are developing rapidly, the scale is bigger and bigger, and the height is higher and higher [1]. The increase of building height leads to the increase of gravity load, so that the vertical components of the structure, especially the cross-section of columns increase. Steel pipe concrete because of its high bearing capacity, good shock resistance, saving steel, effectively improve the seismic performance of the structure, the component size decreases and the comprehensive economic indicators of construction is improved, which are widely used in high-rise buildings and other structures. The steel pipe used in concrete filled steel tubular columns has the following forms, namely straight seam welded pipe, spiral welded pipe and seamless steel pipe. Butt welds must be used when welding, and the strength requirements of the base material are achieved. The steel used in the structure should be checked in batches. Each batch is made up of the same size, the same variety, the same brand, the same grade, the same tank number and the same delivery state steel. In order to meet the requirements of the axis of the steel pipe splicing, the end of the pipe groove should be strictly perpendicular to the axis of the pipe. In the process of rolling, the end plane of the tube should be guaranteed to be perpendicular to the axis of the tube. When the use of rolling reel and manual welding, should adopt welding machine for anti-weld construction. In the hoisting, the upper part of the steel pipe column is sealed to prevent the foreign body from falling into the pipe. After the steel pipe column is hoisted in position, the steel pipe column is corrected immediately, and the temporary fixing measures are taken to ensure the stability of the component. Column lifting, the upper section of steel column base on the center line and the center line of the steel column under the top section of the alignment through the temporary lug on the stigma and the connecting plate, temporary fixed sets of torcher type high strength bolt. The steel tube of the concrete filled steel tube column has the function of steel bar, which has the effect of both longitudinal and transverse reinforcement [2].

\section{Destruction Models of Rectangular Concrete-Filled Steel Tubular Column under Earthquakes}

Bending failure is easy to occur when the column shear span ratio is large, the axial compression ratio is small, and the reinforcement is reasonable. Due to the control of flexural bearing capacity and 
the yield of tensile longitudinal reinforcement, the concrete column to the ultimate compressive strain after plastic deformation, the corresponding force of flexural bearing capacity is smaller than that of shear bearing capacity. Failure: the column plastic hinge area, distribution of horizontal bending cracks, longitudinal plastic hinge reinforcement after yielding, concrete crushing destruction, the larger absorb seismic energy, formed into ductile failure: Grand column in seismic design is that shear failure, due to the influence of objective conditions, design the process can not completely avoid shear failure, and the ability to deal with the control of structure deformation. The deformation of the member increases, resulting in the yield of the longitudinal reinforcement and the plastic hinge at the end of the column. With the continuous expansion of the shear crack, the effective shear area of concrete decreases gradually, and the shear capacity of the column decreases with the increase of deformation. When the deformation continues to increase, the stirrup begins to yield, and the ultimate compressive strain of the compression edge concrete is insufficient after the shear failure. In the course of the whole process, the longitudinal tendons yield, the steel bar is exposed, and the longitudinal reinforcement is pressed. Before bending shear failure, component bending response Peru, has certain ductility. Under the conditions of large axial compression ratio, small shear span ratio and insufficient confinement constraint, shear failure is easy to occur. Because the stirrup is insufficient, the stirrup is limited, and the hoop hook is ninety. The other factors are the important factors that lead to the shortage of stirrup constraints. With the increase of the shear strength, the horizontal force of the column begins to decrease with the increase of the shear bearing capacity. The shear slip cracks of concrete are obvious, and there is brittle failure and no ductility [3].

\section{Experiment Results of Rectangular Concrete-Filled Steel Tubular Column under Earthquakes}

\subsection{Summary of the Experiment}

Serious corrosion on the safety and durability of the concrete structure, longitudinal reinforcement and steel skeleton corrosion damage will lead to longitudinal reinforcement of concrete column crack of concrete spalling failure gradually [4]. The way resulting in the decrease of bearing capacity, seriously affect the overall performance and quality of test node structure damage of corroded reinforced concrete columns in under low cyclic loading analysis, to study its effect on the performance of reinforced concrete columns. There are 13 specimens of reinforced concrete columns. The section diameter of the soil column is $260 \mathrm{~mm}$, the height is $1000 \mathrm{~mm}$, the shear span ratio is 3.15 , the base is $400 \mathrm{~mm} * 360 \mathrm{~mm} * 1300 \mathrm{~mm}$, the thickness of the protective layer is $30 \mathrm{~mm}$, the section size and the reinforcement are reinforced. The water cement ratio of 0.65 , the concrete strength grade C25 grade HPB235 steel stirrups, diameter $8 \mathrm{~mm}, 327 \mathrm{MPa}$ yield strength, ultimate strength of 510.7MPa; longitudinal reinforcement for HRB335 hot-rolled ribbed bar, diameter 16mm, 373.2MPa yield strength, ultimate strength of 572.3MPa. In addition to specimen C0 - 15C0 - 25C0 - 40, the rest are steel corrosion specimens corrosion specimen surface visible along the longitudinal reinforcement of cracks and corrosion, crack length is about $800 \mathrm{~mm}$, the maximum width of up to $2.5 \mathrm{~mm}$ will try out in corrosion of longitudinal bars, with $10 \%$ hydrochloric acid cleaning by using lime water rinse after neutralization, then rinse clean on the corrosion of specimens reinforced the weight loss rate was calculated. The result shows that, in addition to the specimen of $\mathrm{C} 425$, the remaining specimens reinforced the weight loss rate of $9-15 \%$ stirrup diameter ratio of longitudinal reinforcement diameter, stirrup corrosion is more severe in specimen C14 - 32C12 - 90C15 - 90C13 75 stirrup corrosion is very serious, which leads to the decrease of effect of confined concrete.

\subsection{Hysteretic Curve}

The pinching effect test pieces of the $\mathrm{F}$ and the top lateral load displacement hysteretic curves have different degree, occurrence of shear failure of R2 specimens and R3 specimens and R10 specimens, R18 hysteretic curves are relatively full. Except for R11 specimen and R16 specimen, the effect of shearing and bond failure is obvious, and the hysteresis curve is arcuate. In the early stage of loading, 
but the ultimate stage caused by the development of bond failure resulted in a sharp decline in bearing capacity. Under the action of repeated horizontal shear and bending moment, horizontal bending cracks and shear slanting cracks are first appeared at both ends. Bending shear failure section a, Section A is approximately equal to the height of section; in the B section, if the longitudinal reinforcement stress is large enough and the concrete is not enough to provide sufficient anchorage length, when prone to bond failure. If the B is too small, specimens with shear failure, it is difficult to bond failure occurred. Considering the anti-shear strength degradation problems such as stiffness decreases and the shear failure stage of shear cracking caused by using piecewise linear relationship column shear shear displacement under monotonic loading, and as the skeleton curve of column shear shear displacement under cyclic loading hysteretic relationship. Because of the symmetrical reinforcement, the shear lag curve of the reinforced concrete column has good symmetry, so the skeleton curve is positive and negative symmetry. The shear shear displacement skeleton curves obtained by the above method are in good agreement with the measured results, and the calculated results are larger than the experimental results. For specimens with significantly smaller shear capacity than those with bending capacity, brittle failure is more obvious. After reaching the maximum shear force, they enter the shear failure stage, and then their mechanical properties are dominated by shear. A plastic hinge is formed at the end of the column. When it reaches the maximum shear force, it does not enter the stage of shear failure. Instead, it forms a failure diagonal crack after the displacement reaches a certain value, and its mechanical property is dominated by shear.

\subsection{Aseismic Capacity Analysis}

The ductility and energy dissipation index of foreign countries are used to compare the ductility seismic capacity of the specimens. Although their ductility and energy dissipation ability are superior to those of other specimens, the ultimate failure is still due to the bond splitting of concrete, rather than the shear failure of the main shear failure surface. Repeated load test on the intact specimen, the specimen tensile zone of horizontal crack root concrete under repeated load increases, resulting in horizontal crack widening, appears in the compression area of vertical cracks, and concentrated in the root range, because of the crushing of concrete specimens resulting in damage is bending failure. As the bond strength of the reinforced concrete and the corroded steel is reduced, the horizontal crack before yield is less than that of the non-corroded specimen. After yielding, the new horizontal cracks are not obvious, the vertical cracks are wide, and there are no slanting cracks in the loading process. Because of the increase of horizontal load, the cracks widen gradually and develop into slanted cracks. Under continuous loading, new cracks appear on the compression side, and the reinforced bar yield. After yielding, the vertical cracks and slanting cracks continue to extend, after the concrete peeling, the longitudinal tendons are exposed and yielded, and the stirrups yield and break and cause brittle failure. In some cases, the corrosion degree is serious. The restraint effect of concrete stirrup is disappearing, and the shear capacity decreases. Because the yield of the stirrup or the broadening of the diagonal crack make the brittle failure obvious.

\section{Quality Control and Key Technologies of Rectangular Concrete-Filled Steel Tubular Column}

\subsection{Quality Control}

The structure of super high rise rectangular steel tube is more complex, and the technical requirements for the fabrication of steel tube columns are also high. The quality control of the steel pipe column processing should be controlled from each process. Especially for the control of cutting precision, the cutting precision control should be carried out according to the requirements of the construction technology of the super high rise rectangular concrete-filled steel tube column. In addition, before the steel pipe column processing, control to the quality of the materials, especially to check whether the welding material corrosion phenomena such as steel tube under the influence of moisture and water, the surface will be oxidized, and the welding part is connected will affect the 
oxidation of the firmness of the steel pipe will cause crack phenomenon in the late therefore, before use, processing of steel pipe column, we must do the quality control before processing. Steel columns can be become the backbone of the high-rise building, the welding process is an important link between the steel pipe column connection, once welding quality problems, will cause the main problems for the high-rise building, high-rise building construction accidents. Therefore, the quality control of the construction of the super high rise rectangular steel tube concrete column must be done well in the welding process. First of all, to inspect the welding steel pipe material, meets the design requirements of high-rise materials, at the same time, the welding should be carried out strictly according to the welding process guidance, ensure the welding process in accordance with the standard of evaluation. Secondly, to control the welding sequence, mainly follow node symmetry, symmetrical structure, full symmetry principle, at the same time, carefully check on to the various components of the welding, ensure the welding quality of the group, at the same time will each welding process parameter monitoring and recording. Finally, the appearance of the part of the weld must be examined. Once the problem of disqualification is found, it should be repaired and processed in time until the acceptance of the welding is qualified.

\subsection{Key Technologies}

The welding technology of steel tube is one of the important construction techniques in the construction of super high rise rectangular concrete filled steel tubular column. When welding the opposite parts, ensure that two welded steel pipe counterpart and centerline must be in a straight line. At the same time, check the welding interface, do not appear the phenomenon of misalignment and gap. We need to groove in the welding process, while ensuring the inclination angle control of the groove. In addition, under the ditch in the pipe before the first gas turbine or the used sand cut, the hammer and the flat shovel will cut the edge after the processing, to ensure smooth edges without leaving any residue, ensure clean incision, so as to ensure the quality of steel pipe welding, welding to avoid cracks the phenomenon of. As for the drying process of steel pipe welding technology, it is well known that during welding process of steel pipe, if there is water droplet or moisture on the electrode, it will directly affect the quality of steel pipe welding, and drying treatment is an important measure to eliminate moisture and moisture removal on the electrode. In order to avoid the problem of cracking of the welding rod skin caused by the temperature difference between heating and cooling, we should gradually heat up and cool down slowly, so as to effectively avoid the cracking phenomenon of the welding rod. The construction technology of high-rise concrete filled rectangular steel tubular column is inseparable from the concrete construction technology, and the concrete construction technology is also one of the key technologies that affect the quality of the whole super high-rise building, especially the strength of concrete is more important. The concrete construction technology mainly pays attention to the ratio of materials and the construction steps in the construction process.

\section{Conclusions}

In the earthquake, reinforced concrete columns are susceptible to serious damage, resulting in the collapse of bridge housing pillar structure buildings, seriously endanger the safety of life and property of the people in the earthquake process. In addition to bending failure, plastic hinge caused by bending shear failure occurs are relatively rare. We need to strengthen the quality control of concrete filled rectangular steel tubular columns and the key technology to resist earthquake damage.

\section{References}

[1] Wen Yang, Yu Yang, Yang Zheng, et al. Experimental research on plastic hinge length of a three-layer rectangular concrete filled steel tube frame [J]. Building Structure, 2017, 47(23): 61-65+45.

[2] Cai Mao, Gu Xianglin, Hua Jingjing, et al. Seismic response analysis of reinforced concrete 
columns considering shear effects [J]. Journal of Building Structures, 2011, 32(11): 97-108.

[3] Ding Yongjun, Shang Kuijie, Wan Fanggui. Experimental research and nonlinear FEA on seismic behavior of square concrete-filled tubular column to H-shape steel beam connection [J]. Journal of Building Structures, 2012, 33(2): 93-99.

[4] Sun Zhiguo, Si Bingjun, Guo Xun, et al. Experimental Research on the Shear-Bond Failure of Rccolumns under Seismic Action [J]. Engineering Mechanics, 2011, 28(3): 109-117+149. 